OPEN ACCESS

Edited by:

Yuan Shi,

Children's Hospital of Chongqing Medical University, China

Reviewed by:

Ulrich Herbert Thome Leipzig University, Germany Jonathan Michael Davis, Tufts University, United States

${ }^{*}$ Correspondence: Per Torp Sangild

pts@sund.ku.dk

†These authors share first authorship

Specialty section: This article was submitted to Neonatology, a section of the journa

Frontiers in Pediatrics

Received: 04 November 2020 Accepted: 21 January 2021

Published: 11 February 2021

Citation:

Bæk O, Cilieborg MS, Nguyen DN, Bering SB, Thymann T and Sangild PT (2021) Sex-Specific Survival, Growth,

Immunity and Organ Development in Preterm Pigs as Models for Immature Newborns.

Front. Pediatr. 9:626101

doi: 10.3389/fped.2021.626101

\section{Sex-Specific Survival, Growth, Immunity and Organ Development in Preterm Pigs as Models for Immature Newborns}

\author{
Ole Bæk ${ }^{1 \dagger}$, Malene Skovsted Cilieborg ${ }^{1 \dagger}$, Duc Ninh Nguyen ${ }^{1}$, Stine Brandt Bering ${ }^{1}$, \\ Thomas Thymann ${ }^{1}$ and Per Torp Sangild ${ }^{1,2,3 *}$ \\ ${ }^{1}$ Comparative Pediatrics and Nutrition, Faculty of Health and Medical Sciences, University of Copenhagen, Frederiksberg, \\ Denmark, ${ }^{2}$ Department of Neonatology, Rigshospitalet, Copenhagen, Denmark, ${ }^{3}$ Department of Pediatrics, Odense \\ University Hospital, Odense, Denmark
}

Background: After very preterm birth, male infants show higher mortality than females, with higher incidence of lung immaturity, neurological deficits, infections, and growth failure. In modern pig production, piglets dying in the perinatal period (up to 20\%) often show signs of immature organs, but sex-specific effects are not clear. Using preterm pigs as model for immature infants and piglets, we hypothesized that neonatal survival and initial growth and immune development depend on sex.

Methods: Using data from a series of previous intervention trials with similar delivery and rearing procedures, we established three cohorts of preterm pigs ( $90 \%$ gestation), reared for 5,9 , or 19 days before sample collection (total $n=1,938$ piglets from 109 litters). Partly overlapping endpoints among experiments allowed for multiple comparisons between males and females for data on mortality, body and organ growth, gut, immunity, and brain function.

Results: Within the first 2 days, males showed higher mortality than females (18 vs. $8 \%, P<0.001$ ), but less severe immune response to gram-positive infection. No effect of sex was observed for thermoregulation or plasma cortisol. Later, infection resistance did not differ between sexes, but growth rate was reduced for body (up to $-40 \%$ ) and kidneys $(-6 \%)$ in males, with higher leucocyte counts $(+15 \%)$ and lower CD4 T cell fraction $(-5 \%)$ on day 9 and lower monocyte counts $(-18 \%$, day 19 , all $P<0.05)$. Gut structure, function and necrotizing enterocolitis (NEC) incidence were similar between groups, but intestinal weight $(-3 \%)$ and brush-border enzyme activities were reduced at day 5 (lactase, DPP IV, $-8 \%$ ) in males. Remaining values for blood biochemistry, hematology, bone density, regional brain weights, and visual memory (tested in a T maze) were similar.

Conclusion: Following preterm birth, male pigs show higher mortality and slower growth than females, despite limited differences in organ growth, gut, immune, and 
brain functions. Neonatal intensive care procedures may be particularly important for compromised newborns of the male sex. Preterm pigs can serve as good models to study the interactions of sex- and maturation-specific survival and physiological adaptation in mammals.

Keywords: sex, gender, preterm, immune, animal model, cohort

\section{INTRODUCTION}

Across the lifespan, overall morbidity and mortality is higher in males than in females, caused by a multifaceted interaction among biological factors, societal conditions, and environmental determinants (1). The physiological mechanisms of the interacting sex- and age-related morbidities remain unknown and studies indicate that the male deficits are greatest at short gestational age at birth (2). Males are overrepresented among preterm infants and show an increased post-natal mortality compared with their female counterparts (3). Male sex is more prevalent with decreasing gestational age at birth, suggesting that male sex itself may be a risk factor for preterm birth (4). After preterm birth, deficient respiratory and immune functions may increase mortality $(4,5)$, potentially linked to later reduced body growth $(6,7)$ and more frequent neurological sequelae (4). While such complications may be specific for preterm birth, indications of increased mortality of term male infants, across the entire lifespan, imply that differences in survival capacity may exist between sexes, even after term birth $(1,8)$.

It is unknown if neonatal survival and adaptation is sex-specific across mammalian species. For pigs, perinatal mortality is high (15-25\%) in both modern and traditional farming systems (9-15). A higher male piglet mortality is reported for outdoor, extensive systems with moderate litter size $(16,17)$ and impaired locomotion, hypothermia and lacking energy and passive immunity via sow's colostrum have been suggested as causative factors for increased male mortality (16). Intensive breeding programs for prolonged lean tissue growth (physiological immaturity) and large litter size in highintensity facilities may increase the number of weak piglets (1820). Considering the above knowledge of sex-specific effects for preterm infants, this may increase sex-specific neonatal morbidities for modern piglets. Pig growth rates and litter size are top in the world in Denmark (mean 18, range 15-30 piglets/sow) and perinatal mortality remains high, despite genetic selection for survival $(9,21)$. Previous studies in preterm pigs suggest that the combination of immaturity and growth restriction at birth negatively affects systemic and gut immunity (22-25).

Among the immune-related morbidities in preterm infants, necrotizing enterocolitis (NEC), a serious gut inflammatory disorder (26), does not appear to differ between males and females, although few studies report higher NEC incidence in males (27). Conversely, sex-specific differences in systemic immunity complications are reported, and full-term male infants show weaker innate and adaptive immunity, reduced vaccine response and poorer pathogen clearance $(8,28)$. These results indicate fundamental sex-specific differences in systemic immune functions, possibly driven by sex hormones, because differences accelerated after puberty in the above studies. Other hormones, such as glucocorticoids, critical for neonatal maturation and survival across many species, could also play a role for sex-specific survival after term birth $(29,30)$. Less is known for immature infants, but because sex-specific differences may manifest themselves already in utero (31), it is plausible that immaturity at birth pre-dispose to sex-specific effects on morbidity and mortality. Further, maternal inflammation and infection are known to affect infant immunity both in the neonatal period and beyond (32, 33). Male term and preterm infants also have higher risk of positive blood cultures and sepsis, indicating a higher post-natal sensitivity to infection $(4,34)$, and cord blood from male infants show greater pro-inflammatory response to lipopolysaccharide (LPS) (35). However, in other studies cord blood mononuclear cells from term and preterm infants did not show sex-specific differences in response to Tolllike receptor agonists (36). While these data confirm sexspecific responses and morbidities in some, but not all, human studies, they do not provide insight into mechanisms and whether sex effects exist across mammals with/without preterm birth. Observational studies in preterm infants provide limited insight into organ-specific mechanisms and results are often confounded by variable fetal conditions, gestational ages and post-natal treatments.

During 20 years, we have conducted numerous experiments with preterm pigs as models for preterm infants and immune-compromised newborn production pigs, using similar procedures for delivery (elective cesarean section at $90 \%$ gestation) and neonatal care (e.g., incubator rearing with supplemental oxygen, heating, and parenteral/enteral nutrition) (37, 38). This animal model has been used to assess effects of immaturity itself (reduced gestational age at birth) (39-45) and dietary, microbial and pharmacological interventions on nutritional (46), gastrointestinal (47, 48), immune $(49,50)$, and neurological endpoints (51-54). Across these separate experiments, no consistent sex-specific effects were reported. Larger cohorts of preterm pigs, across variable clinical complications and interventions, may be required to demonstrate sex-specific effects. We hypothesized that cohorts of preterm pigs, like preterm infants, show increased mortality of male offspring, potentially related to sex-specific development of organ growth and gut, immune and brain functions. This knowledge may help to define the need for sex-specific care procedures in pig production (e.g., intensive care procedures, artificial rearing, cross-fostering) as well as in human neonatatology. 
TABLE 1 | Overview of cohorts of preterm pigs.

\begin{tabular}{lccccc}
\hline $\begin{array}{l}\text { Duration } \\
\text { (days) }\end{array}$ & $\begin{array}{c}\text { Preterm pigs } \\
\text { total } \boldsymbol{n}\end{array}$ & $\begin{array}{c}\text { Litters } \\
\boldsymbol{n}\end{array}$ & $\begin{array}{c}\text { Separate } \\
\text { studies } \boldsymbol{n}\end{array}$ & $\begin{array}{c}\text { Females } \\
\boldsymbol{n}\end{array}$ & $\begin{array}{c}\text { Males } \\
\boldsymbol{N}\end{array}$ \\
\hline 5 & 1,398 & 79 & 27 & 698 & 700 \\
9 & 319 & 18 & 5 & 163 & 156 \\
19 & 221 & 12 & 5 & 104 & 117 \\
\hline
\end{tabular}

\section{METHODS}

\section{Animals and Their Treatment}

All animal experiments were conducted under a license from the Danish National Committee on Animal Experimentation (2014-15-0201-00418). We compiled a database from previous experiments performed with preterm pigs 2009-2020, all using the same delivery procedures and rearing facilities (37). For all measured outcomes in total 1,938 preterm pigs from 109 litters across 37 experiments (Table 1), we collected sex-specific results when the same outcome parameter was measured across several experiments (aiming to have $n>100$ for each sex). Across the different experiments, preterm pigs were reared for $4-5,8-9$, or 19 days and the three cohort groups were denoted 5, 9, and 19 day cohorts. An overview of the number of pigs, litters and experiments with specific interventions related to diet (e.g., feeding of formula, porcine, bovine or human milk, or colostrum), microbes (e.g., administration of pre-, proand antibiotics) or drugs (e.g., cortisol, IGF-1) is shown in Supplementary Table 1. While some biological endpoints were shared among experiments, other parameters were assessed only in some experiments, resulting in different $\mathrm{n}$ numbers for different parameters for each cohort. For immune endpoints, we first assessed the sex-specific responses to systemic infection for subgroups of pigs younger than 5 days, not included in the 5, 9, or 19 day cohorts (described in detail later).

All pigs (Duroc $\times$ Yorkshire $\times$ Danish Landrace) were delivered by elective cesarean section at 105-106 days gestation (term $=117 \pm 1$ days), and while anesthetized, piglets were fitted with oro-gastric feeding tubes and umbilical arterial lines. The pigs were reared in incubators with supplemental oxygen for the first $12 \mathrm{~h}(1-2 \mathrm{~L} / \mathrm{min})$, extra heating to prevent hypothermia and standardized parenteral and enteral feeding, as described previously (37). In the day 5 cohort, pigs had their rectal temperature taken at $2 \mathrm{~h}$ intervals for the first $12 \mathrm{~h}$ of life (data available for $n=719,49 \%$ male). Furthermore, all pigs were infused with maternal plasma $(16-20 \mathrm{~mL} / \mathrm{kg})$ within the first $24 \mathrm{~h}$ to ensure a standardized level of systemic passive immunity to support immunological protection (e.g., maternal IgG), independent of their sow's colostrum, thus excluding by this artificial rearing system any variability induced by differential piglet-sow interactions. Figure 1 presents an overview of rearing conditions and possible clinical complications in $90 \%$ gestation preterm pigs when reared for 5, 9, or 19 days.

Several different enteral diets and interventions were used in the studies (see Supplementary Table 1) while the same formulation of parenteral nutrition (modified composition of
Kabiven, Fresenius Kabi, Sweden) was used across experiments (41, 48, 51, 55). Across all experiments, pigs were randomly allocated to treatment groups stratified by sex and birth weight, thereby ensuring an even sex distribution in each intervention. During the studies, pigs were euthanized ahead of time if serious complications developed, defined as humane endpoints in accordance with criteria and the license from the Danish National Committee on Animal Experimentation. As described previously (37), the majority of mortalities for preterm pigs reared under such conditions occur within the first $48 \mathrm{~h}$ of life. Therefore, only pigs dying within this early neonatal period were included into mortality data for the present study. Pigs dying from iatrogenic causes (e.g., catheter-related complications with blood loss) were excluded from the analyses. At the end of the pre-defined study periods, all pigs were sacrificed by intracardial injection of phenobarbital after which organ weights were recorded and tissues sampled according to the different study protocols.

\section{Neonatal Mortality and Blood Immunity, Hematology and Biochemistry}

Across all experiments, we identified the litters where mortality within the first $48 \mathrm{~h}$ was accurately reported and noted as spontaneous death or euthanasia. Respiratory distress was commonly observed for such preterm pigs, but a detailed clinical and post-mortem organ investigation of the piglets was not performed. Hematology parameters were evaluated at birth (from the cord, during cesarean delivery), day 9 and day 19 (Advia 2120 Hematology System, Siemens Healthcare Diagnostics, Tarrytown, NY, USA) and plasma biochemistry was recorded at day 19 (Advia 1800 Chemistry System, Siemens, Erlangen, Germany).

Before analyzing organ data for the 5, 9, and 19 day cohorts, we explored the sex-specific differences in neonatal immune response by re-examining data from two previously conducted experiments modeling neonatal sepsis in infants $(23,56)$. These animals were not included among the 5, 9, or 19 day cohorts because the study length was shorter than 5 days. In short, preterm pigs were infused with live Staphylococcus epidermidis $\left(1 \times 10^{8}-5 \times 10^{9} \mathrm{CFU} / \mathrm{kg}\right.$ body weight) bacteria through the umbilical caterer, either few hours after birth $(n=38,53 \%$ male $)$ or after $48 \mathrm{~h}$ ( $n=$ $39,56 \%$ male), without prior provision of maternal plasma. The animals were followed for $24-48 \mathrm{~h}$ and hematological and arterial blood gas parameters evaluated. Animals inoculated with bacteria at birth were kept exclusively on parenteral nutrition whereas those inoculated after $48 \mathrm{~h}$ were supplemented with enteral milk diets. A detailed description of the experimental setup and bacterial inoculation procedure is available (23).

In the 9 day cohort, and in a subgroup of the 5 day cohort ( $n=75,40 \%$ male), spontaneous bacterial infection of the bone marrow was determined. After euthanasia, the femur head was dissected in a sterile manner and a sample of bone marrow collected. This sample was homogenized, serially diluted, plated out on agar and cultured for $24 \mathrm{~h}$. Afterwards, bacterial density 


\section{Preterm pig rearing and complications}

Neonatal care:

Caesarean birth, assisted respiration, passive immunity, parenteral nutrition, thermal support, aseptic conditions

\author{
Postnatal adaptation: \\ Suckling/fluid support, \\ microbial protection, \\ locomotion training
}

Growth and development:

Independent milk drinking and thermoregulation, limited fluid support and microbial protection, independent exploration and learning behaviour

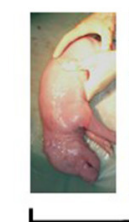

Birth

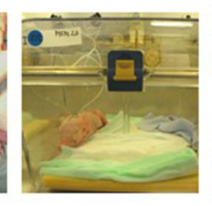

NEONATAL

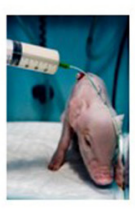

Day 5

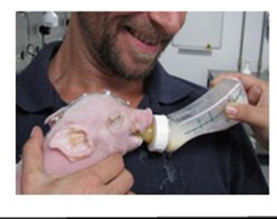

POSTNATAL

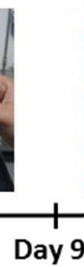

Postnatal risks:

Dysphagia, maldigestion, slow growth, bacteraemia, NEC, motor dysfunction, imbalance

impaired innate immunity, poor neurodevelopment
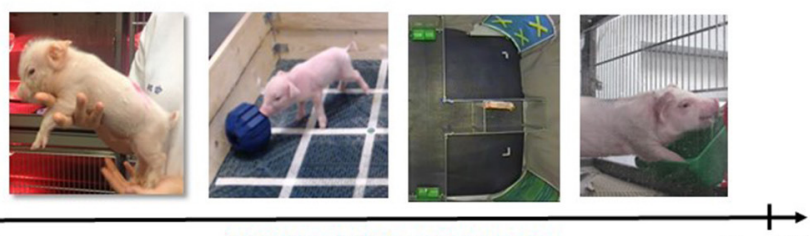

GROWTH/PRE-WEANING

Day 19
Hypoxia, hypovolemia hypothermia, immobility, metabolic dysregulation, NEC, impaired immunity, sepsis, high gut/brain permeability

\begin{abstract}
Growth phase risks:
Delayed body growth, dysregulated metabolism, moderate maldigestion, delayed adaptive immunity, neurodevelopmental delay
\end{abstract}

FIGURE 1 | Illustration of clinical care procedures (green text) and possible morbidities (red text) for cesarean-delivered 90\% gestation preterm pigs, reared as models for preterm infants. Preterm pigs show clinical and physiological characteristics reflecting very preterm infants (<32 weeks gestation) but comparisons to infants are both age- and organ-specific (37). Based on the reports of gender-specific morbidities in preterm infants, we investigate if sex-specific effects are present in preterm pigs at different stages after preterm birth.

was calculated as culture-forming units (CFUs) per milliliter of bone marrow homogenate.

In 9 day pigs, and in a subgroup of day 19 pigs $(n=$ $148,51 \%$ male), flow cytometry (FACS) was used to determine $\mathrm{T}$ cell subsets, as described elsewhere (24). Using fluorescentlabeled antibodies against CD3, CD4, CD8, and FOXP3, the fraction of $\mathrm{T}$ cells, $\mathrm{CD} 4+\mathrm{T}$ cells, $\mathrm{CD} 8+\mathrm{T}$ cells and regulatory $\mathrm{T}$ cells $(\mathrm{CD} 3+\mathrm{CD} 4+\mathrm{FOXP} 3+)$ were established. For the same pigs, the FACS equipment was used to determine neutrophil phagocytic function (57). In short, whole blood samples were incubated with fluorescent-labeled Escherichia coli ( $\mathrm{pH}$ rhodo, Thermofischer, USA) and the phagocytic rate was defined as the fraction of neutrophils with internalized bacteria and the phagocytic capacity as the median fluorescent intensity of those neutrophils.

In the 9 day cohort, leucocyte gene expression at birth was evaluated using cord blood. Using primers against a panel of immune related genes, the relative expression of genes in whole blood, before and after stimulation with LPS, was calculated. Gene expression levels were presented as fold change, relative to a housekeeping gene. The same analysis was repeated at day 9 for a subgroup of animals ( $n=38,53 \%$ male). A full description of the genes investigated and methodologies are published elsewhere (22). Cortisol levels in plasma were measured by enzyme linked immune assay (R\&D systems, USA) in cord blood ( $n=112,49 \%$ male) and at euthanasia in the day 5 ( $n=164,44 \%$ male $)$ and day 19 cohorts $(n=60$, $53 \%$ male).

\section{Growth, Organ Weights and Gut Endpoints}

Body weights at birth and euthanasia were used to calculate growth rate as relative daily weight gains across the study period $(\mathrm{g} / \mathrm{kg} /$ day). At euthanasia, all major internal organs were evaluated and weight relative to body weight recorded. In a subgroup of the 19 day cohort ( $n=86,53 \%$ male) a full body dual-energy X-ray absorptiometry (DEXA, Lunar Prodigy scanner, GE Healthcare, Little Chalfont, UK) was performed at euthanasia to determine body composition, as described previously (41).

Sensitivity to NEC in preterm pigs is highest during the first 1-2 weeks after birth (58), and for the 5 and 9 day cohorts, the stomach, small intestine, and colon was visually inspected post-mortem for signs of inflammation and occurrence of NEC lesions, according to the same validated scoring system, with score 1-2 representing healthy tissue, 3-4 some evidence of NEC lesions, and 5-6 reflecting severe lesions (59). Brush border enzyme activities, including sucrase, maltase, lactase, aminopeptidase $\mathrm{N}(\mathrm{ApN})$, aminopeptidase A (ApA), and dipeptidyl peptidase IV (DPPIV), were evaluated across the small intestine for the 5 and 19-day cohorts (48). Using formalinfixed small intestinal tissue, villus height and crypt depths were determined (48).

\section{Neurodevelopment and Behavior}

Brain weights were recorded and specifically for the 19 day cohort, the brains were further dissected to assess the relative size of each brain region [as percentage of the whole brain (60)]. 
Furthermore, in the 19 day studies, we performed a T maze-test, as a measure of spatial memory (Figure 1), explained in detail elsewhere $(51,52,54)$. Briefly, from 10 days of age preterm pigs were placed in a T-shaped maze with a milk reward in one arm. Using visual clues on the walls, pigs could learn to find the reward following their daily tests in the maze. The number of days until pigs chose the right path in at least $80 \%$ of trials, was considered as the time taken to learn the task. The pigs were also subject to an open field test investigating explorative free movement behavior [Figure 1, (54)].

\section{Statistical Analyses}

All statistical analyses were performed using Stata 14.2 (StataCorp, Texas, USA). Categorical data was compared by Fischer's exact-test and an unadjusted odds ratio, with corresponding confidence interval (CI) calculated. Continuous data were compared using a linear mixed effect model with litter and diet type as fixed factors. Variables that could not conform to normal distribution were logarithmically transformed. If normal distribution could not be obtained, data was compared by Kruskal Wallis'-test. Data collected at several time points were mostly from independent samples and therefore compared separately for each time point. When analyzing immune related endpoints any animals treated with an antibiotic intervention were censored from analysis. Results were presented as means with corresponding standard error of the mean (SE).

\section{RESULTS}

\section{Neonatal Mortality and Blood Immunity, Hematology and Biochemistry}

Across the 109 litters of pigs, there were a mean of 17.8 liveborn piglets per sow (Table 1). Mortality within the first $48 \mathrm{~h}$ was recorded for 833 live-born preterm pigs ( $48 \%$ male) from 18 experiments and 44 of these litters. From these litters, 107 (13\%) died within $48 \mathrm{~h}$ of birth. The mortality was higher in male than female piglets ( 18 vs. $8 \%, P<0.001$ ). The unadjusted odds ratio for male piglets dying within $48 \mathrm{~h}$ compared to female was 2.4 (CI: 1.6-3.8, $P<0.001$ ). Rectal temperatures decreased in the first $3-4 \mathrm{~h}$ after birth, despite being reared in incubators (to $34-35^{\circ} \mathrm{C}$ ), but recovered thereafter to normal temperatures, as shown previously for preterm vs. term pigs (61). The temperature curve during the first $24 \mathrm{~h}$ after birth did not differ between male and female pigs (data not shown).

Hematological parameters at birth did not differ between female and male preterm pigs. By day 9, male piglets had higher total leucocyte counts (Table $2, P<0.05$ ) with a tendency to lower hemoglobin and haematocrit values (Table 2, both $P=$ 0.09). At day 19, the male piglets showed lower hemoglobin concentration and haematocrit values (Table 2, both $P<0.01$ ) with lower monocyte counts (Table $2, P<0.05$ ). Cortisol levels did not differ between the females and males, neither in cord blood (58.0 \pm 2.1 vs. $63.4 \pm 3.4 \mathrm{ng} / \mathrm{mL}, P>0.1)$, at day $5(87.5 \pm$ 9.7 vs. $83.6 \pm 7.5 \mathrm{ng} / \mathrm{mL}, P>0.1)$ or by day $19(60.0 \pm 15.5$ vs. $60.2 \pm 18.2 \mathrm{ng} / \mathrm{mL}, P>0.1)$. Furthermore, no differences in the serum biochemical parameters were found between female and male piglets on day 19, except higher aspartate aminotransferase levels in male piglets (Table 3, $P<0.05$ ).

Animals inoculated with $S$. epidermidis right after birth showed marked sex-specific differences in their responses. Males showed higher neutrophil fractions and platelet counts with lower leucocyte fraction 6-12 h after inoculation (Figures 2A-C, $P<0.05-0.001)$. This result was coupled with a higher blood $\mathrm{pH}$ (Figure 2D, $P<0.05$ ) and oxygen pressure (Figure 2E, $P$ $<0.01-0.001$ ), and with lower blood lactate (Figure 2F, $P<$ 0.001 ). When the same experiment was conducted $48 \mathrm{~h}$ after birth, no differences in hematology or blood gas parameters between females and males were detected (data not shown).

There was no difference in the occurrence of spontaneous bacterial infection in bone marrow on day 5 , but by day 9 , male piglets tended to have a higher infection incidence ( 71 vs. $56 \%$, Figure 3A, $P=0.06)$. However, the bacterial densities in the bone marrow did not differ between females or males, neither at day 5 nor at day 9 (Figure 3B, both $P>0.1$ ). There were no differences in $\mathrm{T}$ cell subsets at birth or by day 19 . However, by day 9 , male preterm pigs showed lower fraction of T cells and CD4 positive T cells (Figures 3 C,D both $P<0.05$ ). Neutrophil phagocytic function did not differ between female and male preterm piglets at birth, day 9 or day 19 (data not shown).

Leucocyte gene expression at birth was performed for 81 preterm pigs (51\% male) and was repeated at day 9 for a smaller subgroup ( $n=38,53 \%$ male). At birth, male piglets showed higher expression of $I L 2$, both before and after stimulation with LPS (Figure 3E, both $P<0.05$ ), male pigs also had higher expression of IFNG after stimulation with LPS (Figure 3F, $P<$ 0.05). Furthermore, male piglets had lower expression of TLR2 and with higher expression of MPO than females (Figures 3G,H, both $P<0.05)$. By day 9 , there was a tendency to higher expression of IL2 in male pigs after LPS stimulation (Figure 3E, $P$ $=0.09$ ). No further differences between female and male preterm pigs were found at day 9.

\section{Growth, Organ Weights and Gut Endpoints}

Mean birth weight did not differ between female and male preterm piglets in any of the pig cohorts and ranged 912-998 g. However, relative daily weight gain was lower in male piglets, both at day 5, 9, and 19 (Figure 4A, all $P<0.05$ ). For organ growth, 5 day male piglets showed lower relative kidney and small intestinal weight (Table 4, $P<0.001$ and $P<0.05$, respectively), with a tendency toward higher relative brain weight (Table 4, $P$ $=0.065)$. In the cohort of pigs reared for 19 days, the relative kidney weight was still lower in male piglets $(P<0.001)$ whereas other organ weights did not differ, apart from a tendency to lower colon weight in male piglets both at day 9 and 19 (Table 4, $P<$ 0.10). No sex-specific differences in body composition at day 19 , as evaluated by DEXA scanning, were found (data not shown).

On day $5,48 \%$ of pigs assessed for NEC $(n=1,152)$ showed mild-severe signs of NEC upon necropsy (score $\geq 3$ in at least one region), while $36 \%$ showed more severe signs (score $\geq 4$ in at least one region), but for both categories, no differences between males and females were observed (Figure 4B). Likewise, there was no difference in the average NEC severity score between males and females, even when stratifying across different regions of the gut 
TABLE 2 | Hematological parameters of female and male preterm pigs on day 1, 9, and 19.

\begin{tabular}{|c|c|c|c|c|c|c|}
\hline & \multicolumn{2}{|c|}{ Day 1} & \multicolumn{2}{|c|}{ Day 9} & \multicolumn{2}{|c|}{ Day 19} \\
\hline & Female $(n=109)$ & Male $(n=116)$ & Female $(n=100)$ & Male $(n=102)$ & Female $(n=92)$ & Male $(n=95)$ \\
\hline Total leucocytes $\left(10^{9}\right.$ cells/L) & $2.7(0.0)$ & $2.8(0.0)$ & $5.6(0.3)$ & $6.4(0.3)^{\star}$ & $9.9(0.6)$ & $9.5(0.4)$ \\
\hline Neutrophils ( $10^{9}$ cells/L) & $0.6(0.0)$ & $0.6(0.0)$ & $3.6(0.3)$ & $4.1(0.3)$ & $7.1(0.8)$ & $6.2(0.4)$ \\
\hline Lymphocytes ( $10^{9}$ cells/L) & $1.9(0.0)$ & $2.0(0.1)$ & $1.8(0.1)$ & $2.0(0.1)$ & $2.8(0.1)$ & $2.8(0.1)$ \\
\hline Monocytes $\left(10^{9}\right.$ cells/L) & $0.06(0.01)$ & $0.05(0.00)$ & $0.13(0.01)$ & $0.15(0.01)$ & $0.38(0.03)$ & $0.31(0.03)^{\star}$ \\
\hline Eosinophils ( $10^{9}$ cells/L) & $0.09(0.01)$ & $0.09(0.01)$ & $0.09(0.05)$ & $0.06(0.01)$ & $0.07(0.01)$ & $0.08(0.01)$ \\
\hline Basophils ( $10^{9}$ cells/L) & $0.01(0.00)$ & $0.01(0.00)$ & $0.02(0.01)$ & $0.01(0.00)$ & $0.02(0.00)$ & $0.02(0.00)$ \\
\hline Platelets $\left(10^{9}\right.$ cells $\left./ L\right)$ & $214(8)$ & 209 (9) & $363(20)$ & $390(22)$ & $479(20)$ & $479(22)$ \\
\hline Red blood cells ( $10^{12}$ cells/L) & $3.7(0.0)$ & $3.8(0.0)$ & $3.4(0.1)$ & $3.5(0.1)$ & $4.0(0.1)$ & $4.0(0.1)$ \\
\hline Hemoglobin (g/L) & $5.2(0.1)$ & $5.2(0.0)$ & $4.4(0.1)$ & $4.2(0.1)\left({ }^{*}\right)$ & $4.4(0.1)$ & $4.3(0.1)^{\star \star}$ \\
\hline Haematocrit (\%) & $28.1(0.3)$ & $28.1(0.3)$ & $23.8(0.4)$ & $23.2(0.4)\left(^{*}\right)$ & $23.5(0.5)$ & $22.9(0.5)^{\star \star}$ \\
\hline
\end{tabular}

Data presented as means with corresponding SE. (") Tendency to effect, $P<0.1,{ }^{*} P<0.05,{ }^{\star *} P<0.01$.

TABLE 3 | Serum biochemistry in female and male piglets at day 19.

\begin{tabular}{lcc}
\hline & Female $(\boldsymbol{n}=\mathbf{9 5})$ & Male $(\boldsymbol{n}=\mathbf{1 0 5})$ \\
\hline Albumin (g/L) & $16.7(0.3)$ & $16.9(0.3)$ \\
Total protein (g/L) & $29.1(0.5)$ & $29.6(0.6)$ \\
Alkaline phosphatase (U/L) & $1,385(81)$ & $1,271(69)$ \\
Alanine aminotransferase (U/L) & $31.3(0.8)$ & $30.7(0.8)$ \\
Total bilirubin ( $\mu$ mol/L) & $2.0(0.1)$ & $2.3(0.1)$ \\
Cholesterol (mmol/L) & $2.7(0.1)$ & $2.7(0.1)$ \\
Creatinine ( $\mu$ mol/L) & $50.8(1.1)$ & $55.5(2.1)$ \\
Creatine kinase (U/L) & $241(21.2)$ & $245(29.5)$ \\
Iron ( $\mu$ mol/L) & $7.2(0.6)$ & $8.2(0.5)$ \\
Phosphate (mmol/L) & $2.1(0.1)$ & $2.1(0.1)$ \\
Aspartate aminotransferase (U/L) & $33.3(1.4)$ & $39.9(2.7)^{\star}$ \\
Blood urea nitrogen (mmo//L) & $3.7(0.3)$ & $4.5(0.4)$ \\
Gamma-glutamyl transferase $(\mathrm{U} / \mathrm{L})$ & $22.4(0.9)$ & $21.9(0.9)$ \\
Calcium (mmol/L) & $2.6(0.0)$ & $2.6(0.0)$ \\
Magnesium (mmol/L) & $0.9(0.0)$ & $0.9(0.0)$ \\
Sodium (mmol/L) & $142(1.3)$ & $143(1.3)$ \\
Potassium (mmo//L) & $4.4(0.1)$ & $4.4(0.1)$ \\
\hline
\end{tabular}

Data presented as means with corresponding $S E .{ }^{*} P<0.05$.

(data not shown). The corresponding values for day 9 piglets with NEC scores $(n=319)$ were 64 and $54 \%$, again with no differences between males and females.

After 5 days, male piglets showed lower activity of lactase and DPPIV (Figure 4C, $P<0.05$ and $P<0.01$, respectively) with a tendency to higher activity of $\operatorname{ApN}(P=0.06)$. In pigs reared for 19 days, there were no differences in brush border enzyme activities (data not shown). Likewise, there were no difference between villus height or crypt depth across gut regions in pigs reared for either 5 or 19 days (data not shown).

\section{Neurodevelopment and Behavior}

On day 19, male pigs had higher absolute weight of cerebellum (2.87 vs. $2.76 \mathrm{~g}, P<0.05)$, and higher relative weights cerebellum (\% of total brain weight, Table 5, $P<0.001$ ), relative to female pigs. Other brain weight measures did not differ. Measured outcomes of motor function, explorative behavior, cognition, and visual memory (open field and T-mazetests), did not show any significant differences between male and female piglets at any time points during the test (data not shown).

\section{DISCUSSION}

To optimize the care and treatment of immature neonates, it is important to know to which extent males and females have different risk factors and respond differently to treatments. Using our preterm pig model of immature birth, we studied preterm male and female pigs during the neonatal transition (5 days), post-natal adaptation (9 days) and initial growth phases of development (19 days, Figure 1). Following elective cesarean section in late gestation, this animal model mimics many of the complications of weak, compromised piglets at term, and of very preterm infants (e.g., immature lung, metabolic, thermoregulatory, gut, immune, and brain functions $(37,38,62)$, yet it avoids the possible confounding effects of fetal factors leading to preterm birth in humans (e.g., maternal inflammation, hypertension, placental dysfunction). Further, our standardized rearing and feeding protocols ensure that we can isolate intrinsic biological differences between the sexes, independent of interactions with their mother for thermoregulation, nutrient uptake or passive immunity. Using this model we now show that neonatal mortality in immature preterm pigs is much higher in male vs. female pigs, despite a seemingly improved resistance to bacterial infection within the first days. There was a clear reduction in body growth in surviving male pigs, but apart from this the observed sex-specific gut, immunity and brain differences were marginal, at least compared with effects of most nutritional, microbial, or pharmacological interventions in preterm pigs (37). How sex-specific differences shortly after preterm birth may develop toward puberty and adulthood remains to be shown, and 

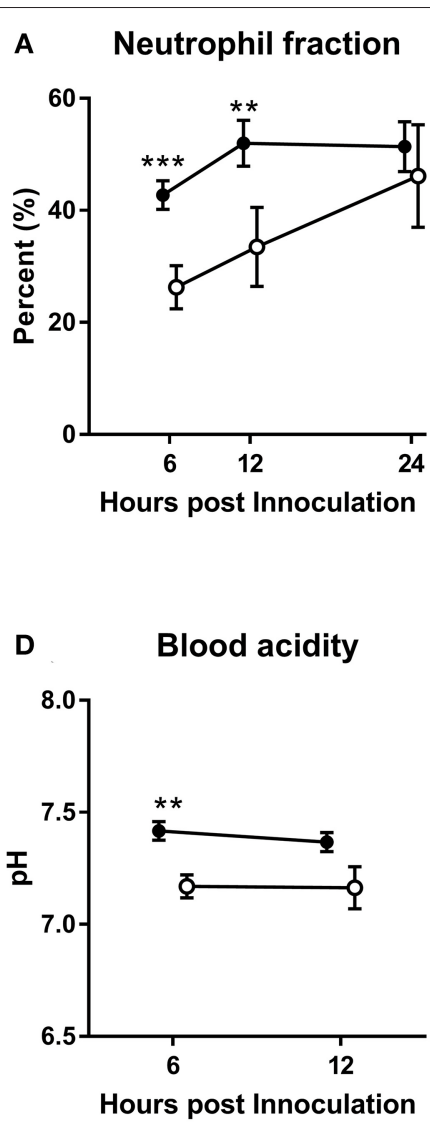
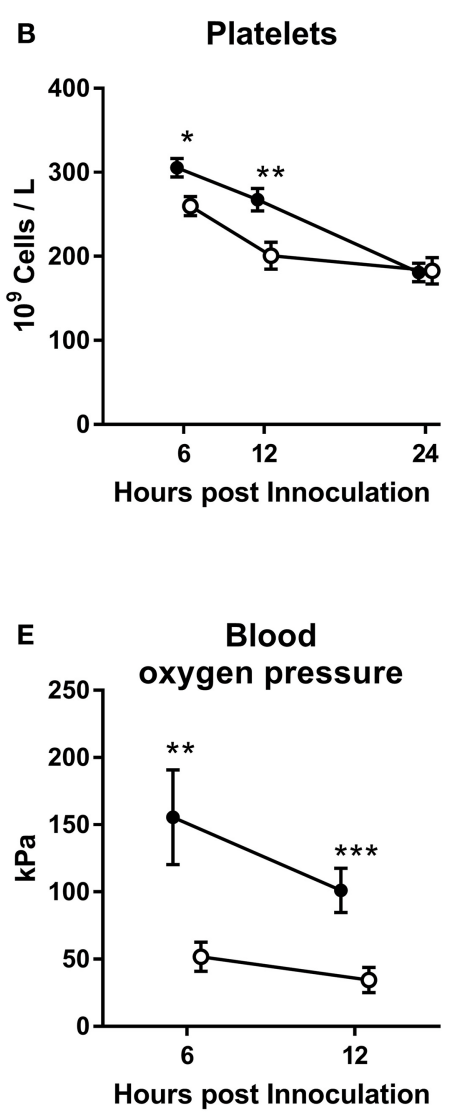

\section{Lymphocyte fraction}
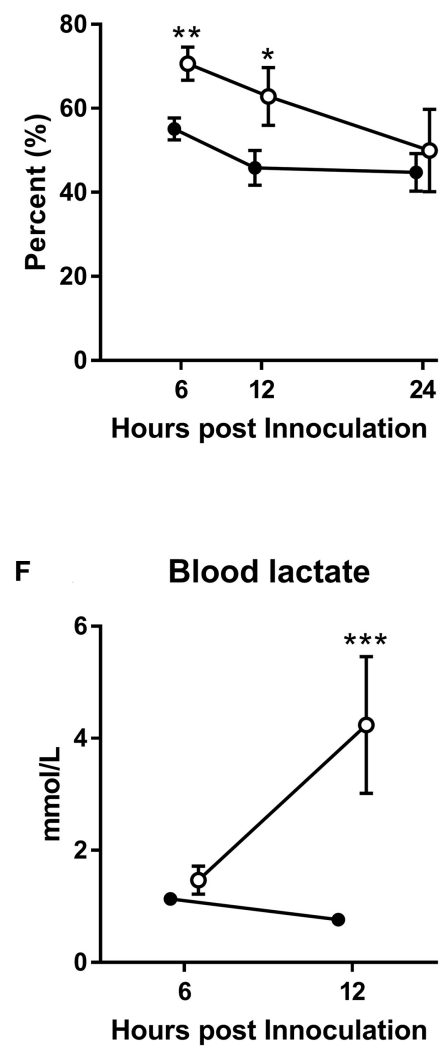

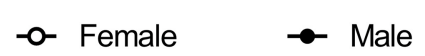

FIGURE 2 | Hematological and blood gas parameters in female and male preterm pigs (open and filled circles, respectively) inoculated with live S. epidermidis bacteria shortly after birth. Neutrophil fractions $(\mathbf{A}, n=38)$. Platelet counts $(\mathbf{B}, n=38)$. Lymphocyte fractions $(\mathbf{C}, n=38)$. Blood acidity $(\mathbf{D}, n=38)$. Blood oxygen pressure $(\mathbf{E}, n=38)$. Blood lactate levels $(\mathbf{F}, n=38)$. All shown as means with corresponding SE. ${ }^{\star} P<0.05,{ }^{\star \star} P<0.01,{ }^{\star \star *} P<0.001$.

in-depth studies on immunity, growth and organ functions are required in both pigs and infants.

Despite the clear difference in neonatal mortality, we are limited by the fact that our preterm pig studies did not include a detailed diagnosis of the cause of death. Yet, studies in infants suggest that poor respiratory function in preterm males is a key contributor to increased mortality (5) and cohort studies have shown that males, both late pre-terms and terms, have higher risk of respiratory distress syndrome (RDS) (63), possibly related to less surfactant production in late gestation $(64,65)$. Following cesarean section at $90 \%$ gestation, a large proportion of preterm pigs show RDS-like symptoms and lung immaturity, as assessed by reduced blood oxygen levels and macroscopic lung appearance at autopsy (atelectasis) (39, $41,57,61)$. However, we have not systematically registered the degree of post-natal respiratory distress in our studies. Interestingly, we did not detect any differences in cord blood levels of cortisol, a hormone well-known to stimulate lung development and respiratory function in preterm infants (66) although differences in cortisol production between the sexes may be masked by the cesarean section that may not stress the piglets as much as preterm labor. We have previously shown that blocking cortisol production in newborn pigs lead to increased neonatal mortality (29). Likewise, low cortisol levels at birth are associated with neonatal mortality in production pigs (30), highlighting the importance of this hormone after birth. Lower body temperature has also been observed in male production pigs and poor thermoregulation was suggested to contribute to increased mortality (16). However, we did not observe any differences in our study in the first $24 \mathrm{~h}$ of life but sexspecific differences in rectal temperature and thermoregulation could have been hidden by our tight control of temperatures in incubators.

Beyond the neonatal period, surviving male preterm pigs in our study showed reduced growth rate, kidney weight and activity of some digestive enzymes. Gut growth was not markedly affected although the slightly reduced intestinal weight on day 5, and tendency to reduced colon weight at day 919, may indeed reflect a slight delay in gut development in males. The magnitude of the transient male-specific reduction in 


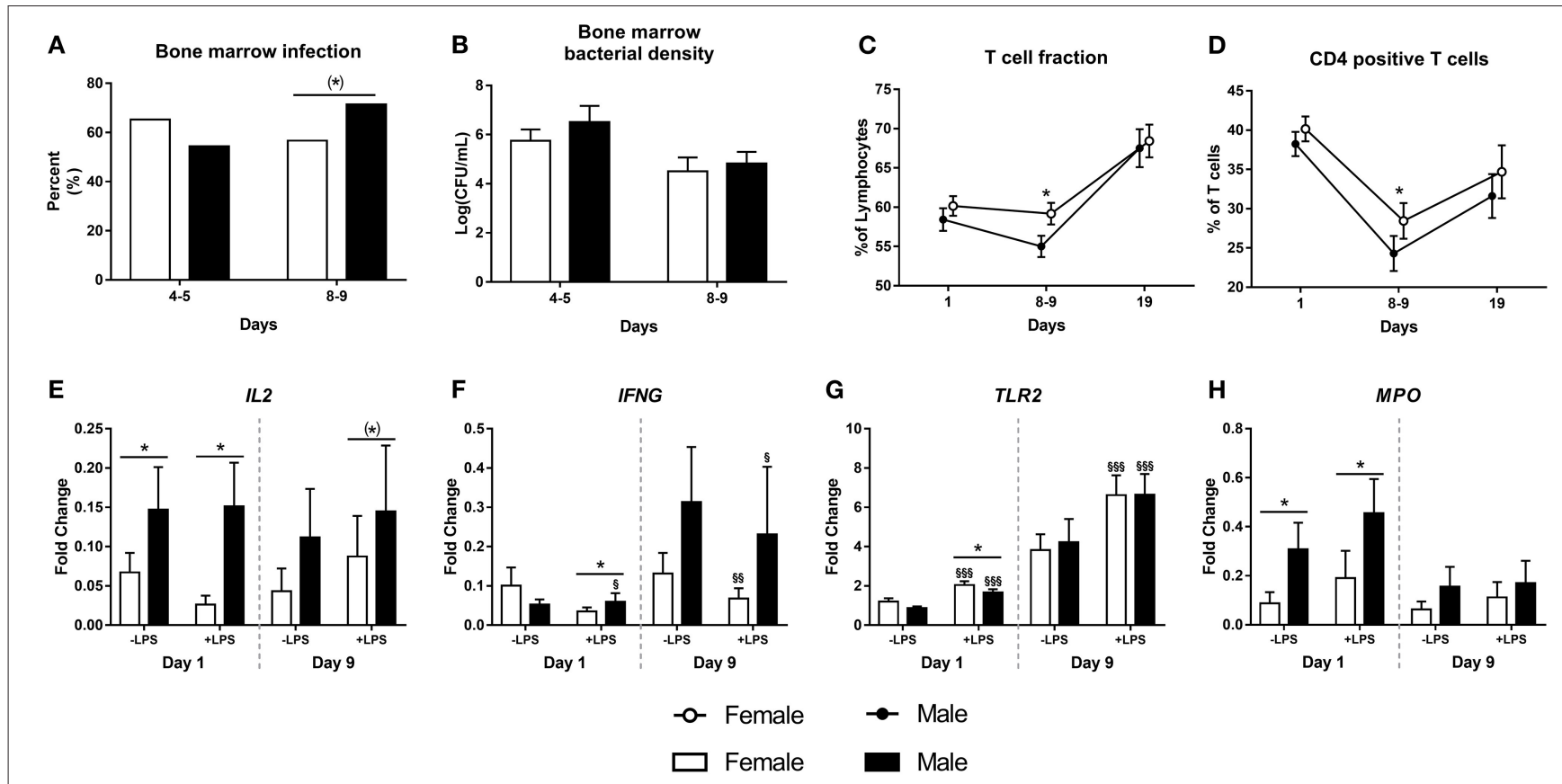

FIGURE 3 | Incidence of bone marrow bacterial infection (A, $n=74$ and 130) with corresponding bacterial densities (B, $n=74$ and 130 ), as well as fractions of T cells (C) $n=52-148$ ), CD4 positive T cells ( $\mathbf{D}, n=52-148)$ and expressions of IL2, IFNG, TLR2, and MPO (E-H, $n=38-81)$ in male and female preterm pigs. Shown as fractions (A), means with corresponding error (B-D) and fold- changes in relation to housekeeping gene, before and after stimulation with lipopolysaccharide (LPS, E-H). $\left({ }^{\star}\right)$ Tendency to an effect, $P<0.1,{ }^{*} P<0.05$. ${ }^{\S}$ Effect of LPS, $P<0.1,{ }^{\S} P<0.05,{ }^{\S} P<0.01,{ }^{\S \S} P<0.001$.

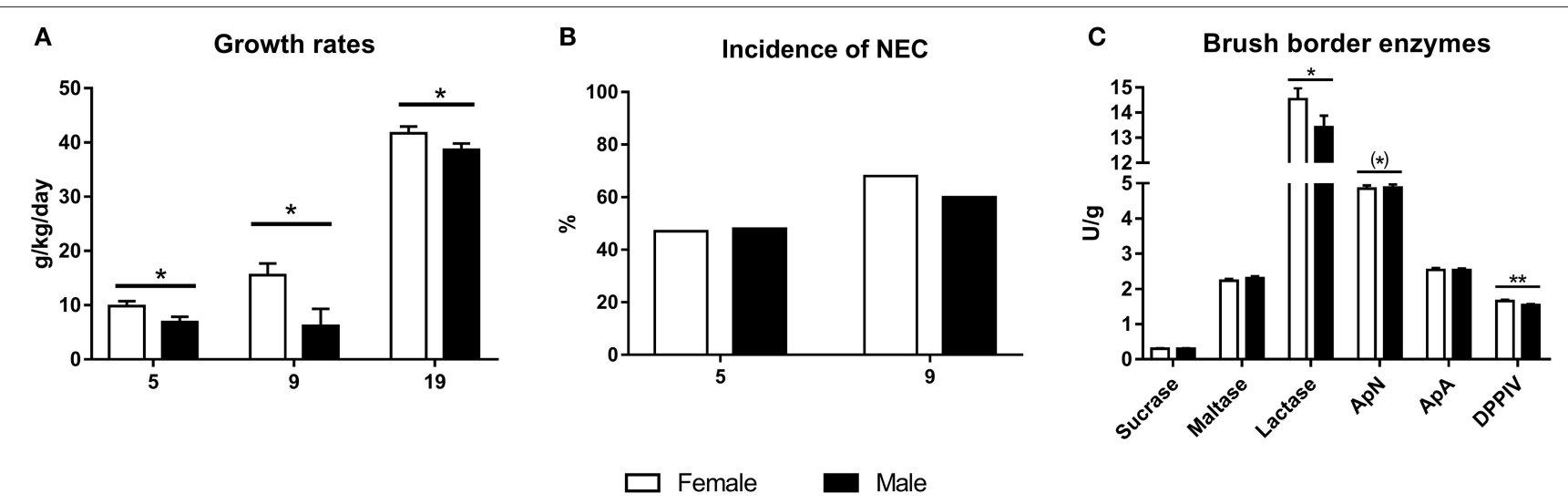

FIGURE 4 | Growth rates for 5, 9, and 19 day cohorts (A, g/kg/day, $n=1,135,319$, and 221), incidence of necrotizing enterocolitis (NEC score $\geq 3$ ) at day 5 and 9 (B, $n=1,152$ for day 5 and $n=319$ for day 9$)$, and brush border enzyme activities at day $5(\mathbf{C}, n=1,028)$ for male and female preterm piglets. Shown as means with corresponding SE $\mathbf{( A , C )}$ or as proportion of animals (\%) in the cohort (B). $\left(^{*}\right)$ Tendency to effect, $P<0.1,{ }^{\star} P<0.05$, ${ }^{\star \star} P<0.01$.

lactase and DPPIV activity on day 5 remained quantitatively of lower magnitude (e.g., 5-10\% reduction) than those of feeding formula vs. intact milk diets or colostrum $(47,67)$ or changes to gut bacterial colonization (relative to germ-free rearing or antibiotics treatment) $(47,55,68)$. The limited effect of sex on gut development and NEC in preterm pigs, despite their high NEC sensitivity in the first 1-2 weeks (37), is consistent with observations in preterm infants, where gender does not markedly affect NEC risk $(27,69,70)$.
The slower body growth in male vs. female preterm pigs is consistent with the finding that male preterm infants are at a higher risk to develop extra-uterine growth restriction $(6,7)$. Among internal organs, only kidney growth was consistently reduced in male preterm pigs. In preterm infants, glomerular filtration rate is similar in males and females (71) but males show a higher risk of acute kidney injury $(72,73)$. At 19 days, male pigs had slightly lower hemoglobin and haematocrit values than females, potentially related to diminished erythropoiesis 
TABLE 4 | Relative organ weights (g per kg body weight) of male and female preterm pigs.

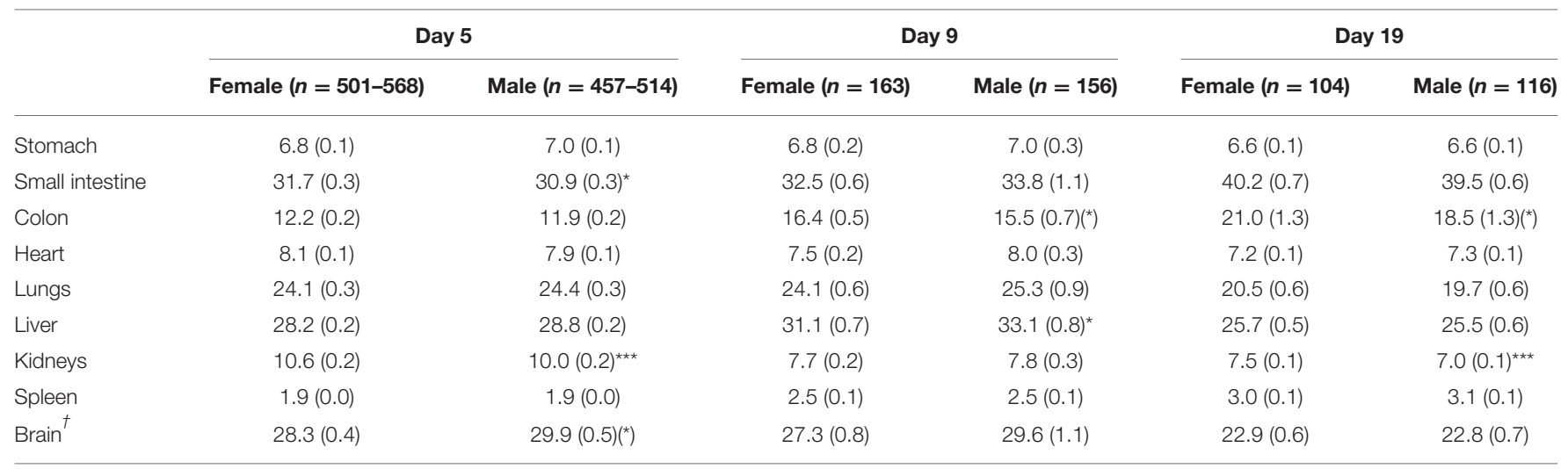

Data are means with corresponding SE. ${ }^{\dagger}$ On day 5 , brains were collected from a subgroup $\left(n=615,47 \%\right.$ male). $\left(^{\star}\right)$ Tendency to effect, $P<0.1,{ }^{\star} P<0.05,{ }^{\star \star \star} P<0.001$.

TABLE 5 | Brain parameters in male and female preterm pigs after 19 days.

\begin{tabular}{lcc}
\hline & Female $(\boldsymbol{n}=\mathbf{1 0 2})$ & Male $(\boldsymbol{n}=\mathbf{1 1 5})$ \\
\hline Water content (\%) & $82.7(0.1)$ & $82.8(0.1)$ \\
Cerebellum (\%) & $10.4(0.1)$ & $10.8(0.1)^{\star \star \star}$ \\
Cerebrum (\%) & $79.9(0.1)$ & $79.7(0.1)$ \\
Brainstem (\%) & $9.2(0.1)$ & $9.3(0.1)$ \\
Hippocampus (\%) & $1.8(0.2)$ & $1.6(0.0)$ \\
Striatum (\%) & $1.0(0.0)$ & $1.0(0.0)$ \\
\hline
\end{tabular}

Data are means with corresponding SE. ${ }^{* \star *} P<0.001$.

by the smaller kidneys (74), but more studies are required to verify sex effects on renal structure and function. This organ could be particularly susceptible to perinatal stressors, as indicated by our recent studies on fetal inflammation on gut, lung, liver, immunity and kidney development in preterm pigs $(33,57,75-77)$. In the literature on production pigs, males do not consistently show reduced neonatal survival and growth $(18-20,30)$, hence sex-specific survival, growth and adaptation may be most pronounced for immature newborns. Consequently, it may become increasingly relevant with sexspecific intensive care procedures for weak (immature) newborn pigs from hyperproliferative sows in modern pig production (e.g., resuscitation, cross-fostering, immunization, artificial rearing procedures, microbial protection).

Important sex-related differences were observed for some systemic immune endpoints just after birth, and these may interact with effects in internal organs. Despite that leucocyte or $\mathrm{T}$ cell subsets did not differ between preterm male and female piglets at birth, the leucocyte gene expression analysis showed that expression of genes encoding interleukin-2 (IL2) and interferon gamma (IFNG) were higher in males, also after stimulation with LPS. Both cytokines are important in development of a Th1-directed immune response (78). Together with a higher expression of myeloperoxidase (MPO) this may have made males more resilient to infection with S. epidermidis. Inoculation with the same bacteria later $(48 \mathrm{~h}$ after birth) showed no differences between male and female piglets. However, the general response to infection was dampened from 2 to 3 days after preterm birth in pigs (23), potentially making sex-specific differences harder to detect from this age. A tendency to a higher rate of spontaneous infection from days 5 to 9 may indicate diminished immune function in males beyond the neonatal period. Staphylococcus epidermidis bacteria are considered pathogenic in preterm infants (79). Male preterm pigs also showed transiently lower $\mathrm{T}$ cell and $\mathrm{CD} 4+\mathrm{T}$ cell fractions at day 9, but these disappeared by day 19 , possibly reflecting age-related data from term 0 to 5 month old infants (80). We cannot exclude that species-specific differences in immune development between pigs and infants, including differential transfer of passive immunity (parentally via the placenta in infants vs. postnatally via colostrum uptake in the gut in pigs), affect our conclusions regarding sex effects. On the other hand, artificiallyreared preterm pigs infused with maternal plasma to provide passive immunity (Figure 1) may very well reflect preterm infants normally born with low plasma levels of $\operatorname{IgG}$ and seldom receive mother's own milk or colostrum as their first enteral meals.

The only neurological parameter that differed between piglet sexes was the size of the cerebellum. While this may indicate better motor function, we saw no sex-related differences in the open field test, nor in the T-maze-test for visual memory capacity. In preterm infants, males have worse neurological outcomes following hypoxia, higher incidence of cerebral palsy and poorer long-term cognitive and language outcomes (81, 82), together with delayed myelination (83). The sex-differences in neurological outcomes are worse after more extreme prematurity (4). In this context, it is important to note that the brain, neurological outcomes and motor function are relatively mature in $90 \%$ gestation preterm pigs, relative to preterm infants, even if they show (temporary) post-natal deficits relative to term piglets $(41,43,45,60)$.

Across a large series of experiments with identical birth conditions (elective cesarean section) and clinically-relevant interventions in the same neonatal care facility, we aimed to mimic and standardize clinical responses to immaturity 
at birth for both pigs and infants. Still, it remains unclear how to translate results from preterm pigs to preterm infants because species similarities and differences are both age- and organ-dependent. Similarly, it remains speculative how well $90 \%$ preterm piglets reflect the clinical complications for the large proportion of normal term pigs dying during delivery or shortly after birth in modern pig production. The inclusion of a large number of endpoints from different cohorts increases the risk of false discoveries in statistical testing, despite large sample size. Regardless, our model provides a well-controlled and sensitive tool to test the effects of interventions and biological co-variants when individuals show immaturity at birth, and without the variable maternal interactions known to influence sex-specific survival rates in both pigs (16) and infants (14). Our results document that preterm pigs mimic many of the sex-specific differences in mortality, growth, and immune functions in preterm infants, supporting the use of this model to investigate sex-specific diseases of immature newborns. The mechanisms related to differences in immune response in the neonatal period, as well as the small effects on body and organ growth and function later (e.g., lung, gut, immunity, brain) warrant further investigations. At the population level, such biological differences may affect clinical outcomes but it remains questionable, if they justify sex-specific clinical treatment of immature and/or mature newborn individuals, either pigs or infants.

\section{DATA AVAILABILITY STATEMENT}

The raw data supporting the conclusions of this article will be made available by the authors, without undue reservation.

\section{REFERENCES}

1. Lozano R, Naghavi M, Foreman K, Lim S, Shibuya K, Aboyans V, et al. Global and regional mortality from 235 causes of death for 20 age groups in 1990 and 2010: A systematic analysis for the Global Burden of Disease Study 2010. Lancet. (2012) 380:2095-128. doi: 10.1016/S0140-6736(12) 61728-0

2. Zisk JL, Genen LH, Kirkby S, Webb D, Greenspan J, Dysart K. Do premature female infants really do better than their male counterparts? Am J Perinatol. (2011) 28:241-6. doi: 10.1055/s-0030-1268239

3. Challis J, Newnham J, Petraglia F, Yeganegi M, Bocking A. Fetal sex and preterm birth. Placenta. (2013) 34:95-9. doi: 10.1016/j.placenta.2012.11.007

4. O'Driscoll DN, McGovern M, Greene CM, Molloy EJ. Gender disparities in preterm neonatal outcomes. Acta Paediatr. (2018) 107:1494-9. doi: 10.1111/apa.14390

5. Townsel CD, Emmer SF, Campbell WA, Hussain N. Gender differences in respiratory morbidity and mortality of preterm neonates. Front Pediatr. (2017) 5:6. doi: 10.3389/fped.2017.00006

6. Clark RH, Thomas P, Peabody J. Extrauterine growth restriction remains a serious problem in prematurely born neonates. Pediatrics. (2003) 111:986-90. doi: 10.1542/peds.111.5.986

7. Figueras-Aloy J, Palet-Trujols C, Matas-Barceló I, Botet-Mussons F, Carbonell-Estrany X. Extrauterine growth restriction in very preterm infant: etiology, diagnosis, and 2-year follow-up. Eur J Pediatr. (2020) 179:1469-79. doi: 10.1007/s00431-020-03628-1

8. Klein SL, Flanagan KL. Sex differences in immune responses. Nat Rev Immunol. (2016) 16:626-38. doi: 10.1038/nri.2016.90

\section{ETHICS STATEMENT}

The animal study was reviewed and approved by Danish National Committee on Animal Experimentation.

\section{AUTHOR CONTRIBUTIONS}

MC collected and organized the cohort data for analysis. OB analyzed data and produced the first draft of the manuscript. PS took responsibility for final editions in the text. All authors commented on the data, analyses and manuscript text, and approved the final version for submission.

\section{FUNDING}

The studies were supported by Grants from Innovation Fund Denmark (NEOMUNE, NEOCOL, InfantBrain), ARLA Foods Ingredients, Danone Baby Nutrition and Biofiber Damino.

\section{ACKNOWLEDGMENTS}

We acknowledge all the students, scientific and technical staff involved in the various animal experiments (see list of experiments in Supplementary Table 1). Christian Ritz is acknowledged for advice on statistical procedures.

\section{SUPPLEMENTARY MATERIAL}

The Supplementary Material for this article can be found online at: https://www.frontiersin.org/articles/10.3389/fped. 2021.626101/full\#supplementary-material

9. Kobek-Kjeldager C, Moustsen VA, Theil PK, Pedersen LJ. Effect of litter size, milk replacer and housing on production results of hyper-prolific sows. Anim Int J Anim Biosci. (2020) 14:824-33. doi: 10.1017/S175173111900260X

10. Pedersen LJ, Larsen ML, Malmkvist J. The ability of different thermal aids to reduce hypothermia in neonatal piglets. J Anim Sci. (2016) 94:2151-9. doi: 10.2527/jas.2015-0219

11. Rangstrup-Christensen L, Krogh MA, Pedersen LJ, Sørensen JT. Sow-level risk factors for stillbirth of piglets in organic sow herds. Anim Int J Anim Biosci. (2017) 11:1078-83. doi: 10.1017/S1751731116002408

12. Pandolfi F, Edwards SA, Robert F, Kyriazakis I. Risk factors associated with the different categories of piglet perinatal mortality in French farms. Prev Vet Med. (2017) 137:1-12. doi: 10.1016/j.prevetmed.2016. 12.005

13. Zeng ZK, Urriola PE, Dunkelberger JR, Eggert JM, Vogelzang R, Shurson GC, et al. Implications of early-life indicators for survival rate, subsequent growth performance, and carcass characteristics of commercial pigs. J Anim Sci. (2019) 97:3313-25. doi: 10.1093/jas/skz223

14. Calderón Díaz JA, Boyle LA, Diana A, Leonard FC, Moriarty JP, McElroy $\mathrm{MC}$, et al. Early life indicators predict mortality, illness, reduced welfare and carcass characteristics in finisher pigs. Prev Vet Med. (2017) 146:94-102. doi: 10.1016/j.prevetmed.2017.07.018

15. Yuan TL, Zhu YH, Shi M, Li TT, Li N, Wu GY, et al. Within-litter variation in birth weight: impact of nutritional status in the sow. J Zhejiang Univ Sci. (2015) 16:417-35. doi: 10.1631/jzus.B1500010

16. Baxter EM, Jarvis S, Palarea-Albaladejo J, Edwards SA. The weaker sex? The propensity for male-biased piglet mortality. PLoS ONE. (2012) 7:e30318. doi: 10.1371/journal.pone.0030318 
17. Bereskin B, Shelby CE, Cox DF. Some factors affecting pig survival. J Anim Sci. (1973) 36:821-7. doi: 10.2527/jas1973.365821x

18. Herpin P, Le Dividich J, Amaral N. Effect of selection for lean tissue growth on body composition and physiological state of the pig at birth. J Anim Sci. (1993) 71:2645-53. doi: 10.2527/1993.71102645x

19. Tuchscherer M, Puppe B, Tuchscherer A, Tiemann U. Early identification of neonates at risk: traits of newborn piglets with respect to survival. Theriogenology. (2000) 54:371-88. doi: 10.1016/S0093-691X(00) 00355-1

20. Silalahi P, Tribout T, Billon Y, Gogué J, Bidanel JP. Estimation of the effects of selection on French large white sow and piglet performance during the suckling period. J Anim Sci. (2017) 95:4333-43. doi: 10.2527/jas201 7.1485

21. Nielsen B, Su G, Lund MS, Madsen P. Selection for increased number of piglets at $\mathrm{d} 5$ after farrowing has increased litter size and reduced piglet mortality. $J$ Anim Sci. (2013) 91:2575-82. doi: 10.2527/jas.2012-5990

22. Bæk O, Ren S, Brunse A, Sangild PT, Nguyen DN. Impaired neonatal immunity and infection resistance following fetal growth restriction in preterm pigs. Front Immunol. (2020) 11:1808. doi: 10.3389/fimmu.2020.01808

23. Bæk O, Brunse A, Nguyen DN, Moodley A, Thymann T, Sangild PT. Diet modulates the high sensitivity to systemic infection in newborn preterm pigs. Front Immunol. (2020) 11:1019. doi: 10.3389/fimmu.2020.01019

24. Bæk O, Sangild PT, Thymann T, Nguyen DN. Growth restriction and systemic immune development in preterm piglets. Front Immunol. (2019) 10:2402. doi: 10.3389/fimmu.2019.02402

25. Che L, Thymann T, Bering SB, I LEH-L, D'Inca R, Zhang $\mathrm{K}$, et al. IUGR does not predispose to necrotizing enterocolitis or compromise postnatal intestinal adaptation in preterm pigs. Pediatr Res. (2010) 67:54-9. doi: 10.1203/PDR.0b013e3181c1b15e

26. Niño DF, Sodhi CP, Hackam DJ. Necrotizing enterocolitis: new insights into pathogenesis and mechanisms. Nat Rev Gastroenterol Hepatol. (2016) 13:590-600. doi: 10.1038/nrgastro.2016.119

27. Carter BM, Holditch-Davis D. Risk factors for necrotizing enterocolitis in preterm infants: how race, gender, and health status contribute. Adv Neonatal Care. (2008) 8:285-90. doi: 10.1097/01.ANC.0000338019.56405.29

28. Muenchhoff M, Goulder PJR. Sex differences in pediatric infectious diseases. J Infect Dis. (2014) 209:120-6. doi: 10.1093/infdis/jiu232

29. Sangild PT, Diernaes L, Christiansen IJ, Skadhauge E. Intestinal transport of sodium, glucose and immunoglobulin in neonatal pigs. Effect of glucocorticoids. Exp Physiol. (1993) 78:485-97. doi: 10.1113/expphysiol.1993.sp003700

30. Leenhouwers JI, Knol EF, de Groot PN, Vos H, van der Lende T. Fetal development in the pig in relation to genetic merit for piglet survival. J Anim Sci. (2002) 80:1759-70. doi: 10.2527/2002.8071759x

31. Goldenberg RL, Andrews WW, Faye-Petersen OM, Goepfert AR, Cliver SP, Hauth JC. The Alabama preterm birth study: intrauterine infection and placental histologic findings in preterm births of males and females less than 32 weeks. Am J Obstet Gynecol. (2006) 195:1533-7. doi: 10.1016/j.ajog.2006.05.023

32. Wolfs TGAM, Jellema RK, Turrisi G, Becucci E, Buonocore G, Kramer BW. Inflammation-induced immune suppression of the fetus: a potential link between chorioamnionitis and postnatal early onset sepsis. J Maternal Fetal Neonatal Med. (2012) 25:8-11. doi: 10.3109/14767058.2012.664447

33. Ren S, Pan X, Gao F, Sangild PT, Nguyen DN. Prenatal inflammation suppresses blood Th1 polarization and gene clusters related to cellular energy metabolism in preterm newborns. FASEB J. (2020) 34:2896-911. doi: 10.1096/fj.201902629R

34. Albers MJIJ, De Gast-Bakker DAH, Van Dam NAM, Madern GC, Tibboel D. Male sex predisposes the newborn surgical patient to parenteral nutrition-associated cholestasis and to sepsis. Arch Surg. (2002) 137:789-93. doi: 10.1001/archsurg.137.7.789

35. Kim-Fine S, Regnault TR, Lee JS, Gimbel SA, Greenspoon JA, Fairbairn $\mathrm{J}$, et al. Male gender promotes an increased inflammatory response to lipopolysaccharide in umbilical vein blood. J Maternal fetal Neonatal Med. (2012) 25:2470-4. doi: 10.3109/14767058.2012.684165

36. Sharma AA, Jen $R$, Brant $R$, Ladd $M$, Huang $Q$, Skoll $A$, et al. Hierarchical maturation of innate immune defences in very preterm neonates. Neonatology. (2014) 106:1-9. doi: 10.1159/000358550
37. Sangild PT, Thymann T, Schmidt M, Stoll B, Burrin DG, Buddington RK. Invited review: the preterm pig as a model in pediatric gastroenterology. $J$ Anim Sci. (2013) 91:4713-29. doi: 10.2527/jas.2013-6359

38. Sangild PT. Gut responses to enteral nutrition in preterm infants and animals. Exp Biol Med (Maywood, NJ). (2006) 231:1695-711. doi: $10.1177 / 153537020623101106$

39. Ren S, Hui Y, Obelitz-Ryom K, Brandt AB, Kot W, Nielsen DS, et al. Neonatal gut and immune maturation is determined more by postnatal age than by postconceptional age in moderately preterm pigs. Am J Physiol Gastrointest Liver Physiol. (2018) 315:G855-67. doi: 10.1152/ajpgi.00169.2018

40. Kamal SS, Andersen AD, Krych L, Lauridsen C, Sangild PT, Thymann $\mathrm{T}$, et al. Preterm birth has effects on gut colonization in piglets within the first 4 weeks of life. J Pediatr Gastroenterol Nutr. (2019) 68:727-33. doi: 10.1097/MPG.0000000000002259

41. Andersen AD, Sangild PT, Munch SL, van der Beek EM, Renes IB, Ginneken $\mathrm{C}$, et al. Delayed growth, motor function and learning in preterm pigs during early postnatal life. Am J Physiol Regul Integr Comp Physiol. (2016) 310:R481-92. doi: 10.1152/ajpregu.00349.2015

42. Aunsholt L, Thymann T, Qvist N, Sigalet D, Husby S, Sangild PT. Prematurity reduces functional adaptation to intestinal resection in piglets. JPEN. (2015) 39:668-76. doi: 10.1177/0148607114528714

43. Bergström A, Kaalund SS, Skovgaard K, Andersen AD, Pakkenberg B, Rosenørn A, et al. Limited effects of preterm birth and the first enteral nutrition on cerebellum morphology and gene expression in piglets. Physiol Rep. (2016) 4:e12871. doi: 10.14814/phy2.12871

44. Hansen CF, Thymann T, Andersen AD, Holst JJ, Hartmann B, Hilsted L, et al. Rapid gut growth but persistent delay in digestive function in the postnatal period of preterm pigs. Am J Physiol Gastrointest Liver Physiol. (2016) 310:G550-60. doi: 10.1152/ajpgi.00221.2015

45. Plomgaard AM, Andersen AD, Petersen TH, van de Looij Y, Thymann T, Sangild PT, et al. Structural brain maturation differs between preterm and term piglets, whereas brain activity does not. Acta Paediatr. (2019) 108:63744. doi: 10.1111/apa.14556

46. Vegge A, Thymann T, Lauritzen L, Bering SB, Wiinberg B, Sangild PT. Parenteral lipids and partial enteral nutrition affect hepatic lipid composition but have limited short term effects on formula-induced necrotizing enterocolitis in preterm piglets. Clin Nutr (Edinburgh, Scotland). (2015) 34:219-28. doi: 10.1016/j.clnu.2014.03.004

47. Sangild PT, Siggers RH, Schmidt M, Elnif J, Bjornvad CR, Thymann T, et al. Diet- and colonization-dependent intestinal dysfunction predisposes to necrotizing enterocolitis in preterm pigs. Gastroenterology. (2006) 130:177692. doi: 10.1053 j.gastro.2006.02.026

48. Thymann T, Møller HK, Stoll B, Støy AC, Buddington RK, Bering $\mathrm{SB}$, et al. Carbohydrate maldigestion induces necrotizing enterocolitis in preterm pigs. Am J Physiol Gastrointest Liver Physiol. (2009) 297:G1115-25. doi: 10.1152/ajpgi.00261.2009

49. Nguyen DN, Stensballe A, Lai JC, Jiang P, Brunse A, Li Y, et al. Elevated levels of circulating cell-free DNA and neutrophil proteins are associated with neonatal sepsis and necrotizing enterocolitis in immature mice, pigs and infants. Innate Immun. (2017) 23:524-36. doi: 10.1177/17534259177 19995

50. Nguyen DN, Jiang P, Frøkiær H, Heegaard PM, Thymann T, Sangild PT. Delayed development of systemic immunity in preterm pigs as a model for preterm infants. Sci Rep. (2016) 6:36816. doi: 10.1038/srep36816

51. Ahnfeldt AM, Bæk O, Hui Y, Nielsen CH, Obelitz-Ryom K, Busk-Anderson $\mathrm{T}$, et al. Nutrient restriction has limited short-term effects on gut, immunity, and brain development in preterm pigs. J Nutr. (2020) 150:1196-207. doi: $10.1093 / \mathrm{jn} / \mathrm{nxaa} 030$

52. Andersen AD, Nguyen DN, Langhorn L, Renes IB, van Elburg RM, Hartog A, et al. Synbiotics combined with glutamine stimulate brain development and the immune system in preterm pigs. J Nutr. (2019) 149:36-45. doi: 10.1093/jn/nxy243

53. Cao M, Brunse A, Thymann T, Sangild PT. Physical activity and spatial memory are minimally affected by moderate growth restriction in preterm piglets. Dev Neurosci. (2019) 41:247-54. doi: 10.1159/000505726

54. Obelitz-Ryom K, Bering SB, Overgaard SH, Eskildsen SF, Ringgaard S, Olesen $\mathrm{JL}$, et al. Bovine milk oligosaccharides with sialyllactose improves cognition in preterm pigs. Nutrients. (2019) 11:1335. doi: 10.3390/nu11061335 
55. Birck MM, Nguyen DN, Cilieborg MS, Kamal SS, Nielsen DS, Damborg P, et al. Enteral but not parenteral antibiotics enhance gut function and prevent necrotizing enterocolitis in formula-fed newborn preterm pigs. Am J Physiol Gastrointest Liver Physiol. (2016) 310:G323-33. doi: 10.1152/ajpgi.00392.2015

56. Brunse A, Worsøe P, Pors SE, Skovgaard K, Sangild PT. Oral supplementation with bovine colostrum prevents septic shock and brain barrier disruption during bloodstream infection in preterm newborn pigs. Shock. (2019) 51:33747. doi: 10.1097/SHK.0000000000001131

57. Nguyen DN, Thymann T, Goericke-Pesch SK, Ren S, Wei W, Skovgaard K, et al. Prenatal intra-amniotic endotoxin induces fetal gut and lung immune responses and postnatal systemic inflammation in preterm pigs. Am J Pathol. (2018) 188:2629-43. doi: 10.1016/j.ajpath.2018.07.020

58. Li Y, Pan X, Nguyen DN, Ren S, Moodley A, Sangild PT. Bovine colostrum before or after formula feeding improves systemic immune protection and gut function in newborn preterm pigs. Front Immunol. (2019) 10:3062. doi: 10.3389/fimmu.2019.03062

59. Siggers J, Sangild PT, Jensen TK, Siggers RH, Skovgaard K, Støy AC, et al. Transition from parenteral to enteral nutrition induces immediate diet-dependent gut histological and immunological responses in preterm neonates. Am J Physiol Gastrointest Liver physiol. (2011) 301:G435-45. doi: 10.1152/ajpgi.00400.2010

60. Holme Nielsen C, Bladt Brandt A, Thymann T, Obelitz-Ryom K, Jiang P, Vanden Hole C, et al. Rapid postnatal adaptation of neurodevelopment in pigs born late preterm. Dev Neurosci. (2018) 40:586-600. doi: 10.1159/000499127

61. Sangild PT, Petersen YM, Schmidt M, Elnif J, Petersen TK, Buddington $\mathrm{RK}$, et al. Preterm birth affects the intestinal response to parenteral and enteral nutrition in newborn pigs. J Nutr. (2002) 132:3786-94. doi: $10.1093 / \mathrm{jn} / 132.9 .2673$

62. Sangild PT, Ney DM, Sigalet DL, Vegge A, Burrin D. Animal models of gastrointestinal and liver diseases. Animal models of infant short bowel syndrome: translational relevance and challenges. Am J Physiol Gastrointest Liver Physiol. (2014) 307:G1147-68. doi: 10.1152/ajpgi.00088.2014

63. Anadkat JS, Kuzniewicz MW, Chaudhari BP, Cole FS, Hamvas A. Increased risk for respiratory distress among white, male, late preterm and term infants. J Perinatol. (2012) 32:780-5. doi: 10.1038/jp.2011.191

64. Fleisher B, Kulovich MV, Hallman M, Gluck L. Lung profile: sex differences in normal pregnancy. Obstet Gynecol. (1985) 66:327-30. Epub 1985/09/01.

65. Dammann CEL, Ramadurai SM, Mccants DD, Pham LD, Nielsen HC. Androgen regulation of signaling pathways in late fetal mouse lung development. Endocrinology. (2000) 141:2923-9. doi: 10.1210/endo.141.8.7615

66. Roberts D, Brown J, Medley N, Dalziel SR. Antenatal corticosteroids for accelerating fetal lung maturation for women at risk of preterm birth. Cochrane Database Syst Rev. (2017) 3:Cd004454. doi: 10.1002/14651858.CD004454.pub3

67. Shen RL, Thymann T, Østergaard MV, Støy AC, Krych $€$, Nielsen DS, et al. Early gradual feeding with bovine colostrum improves gut function and NEC resistance relative to infant formula in preterm pigs. Am J Physiol Gastrointest Liver Physiol. (2015) 309:G310-23. doi: 10.1152/ajpgi.00163.2015

68. Jensen ML, Thymann T, Cilieborg MS, Lykke M, Mølbak L, Jensen BB, et al. Antibiotics modulate intestinal immunity and prevent necrotizing enterocolitis in preterm neonatal piglets. Am J Physiol Gastrointest Liver Physiol. (2014) 306:G59-71. doi: 10.1152/ajpgi.00213.2013

69. Lu Q, Cheng S, Zhou M, Yu J. Risk factors for necrotizing enterocolitis in neonates: a retrospective case-control study. Pediatr Neonatol. (2017) 58:16570. doi: 10.1016/j.pedneo.2016.04.002

70. Ahle M, Drott P, Elfvin A, Andersson RE. Maternal, fetal and perinatal factors associated with necrotizing enterocolitis in Sweden. A national case-control study. PLoS ONE. (2018) 13:e0194352. doi: 10.1371/journal.pone.0194352
71. Abitbol CL, Seeherunvong W, Galarza MG, Katsoufis C, Francoeur D, Defreitas $\mathrm{M}$, et al. Neonatal kidney size and function in preterm infants: what is a true estimate of glomerular filtration rate? J Pediatr. (2014) 164:102631.e2. doi: 10.1016/j.jpeds.2014.01.044

72. Stojanović V, Barišić N, Milanović B, Doronjski A. Acute kidney injury in preterm infants admitted to a neonatal intensive care unit. Pediatr Nephrol (Berlin, Germany). (2014) 29:2213-20. doi: 10.1007/s00467-0142837-0

73. Nagaraj N, Berwal PK, Srinivas A, Berwal A. A study of acute kidney injury in hospitalized preterm neonates in NICU. J Neonatal Perinat Med. (2016) 9:417-21. doi: 10.3233/NPM-161614

74. Adamson JW, Eschbach J, Finch CA. The kidney and erythropoiesis. Am J Med. (1968) 44:725-33. doi: 10.1016/0002-9343(68)90254-4

75. Muk T, Jiang PP, Stensballe A, Skovgaard K, Sangild PT, Nguyen DN. Prenatal endotoxin exposure induces fetal and neonatal renal inflammation via innate and Th1 immune activation in preterm pigs. Front Immunol. (2020) 11:565484. doi: 10.3389/fimmu.2020.565484

76. Pan X, Zhang D, Nguyen DN, Wei W, Yu X, Gao F, et al. Postnatal gut immunity and microbiota development is minimally affected by prenatal inflammation in preterm pigs. Front Immunol. (2020) 11:420. doi: 10.3389/fimmu.2020.00420

77. Ren S, Hui Y, Goericke-Pesch S, Pankratova S, Kot W, Pan X, et al. Gut and immune effects of bioactive milk factors in preterm pigs exposed to prenatal inflammation. Am J Physiol Gastrointest Liver Physiol. (2019) 317:G67-77. doi: 10.1152/ajpgi.00042.2019

78. Levy O. Innate immunity of the newborn: basic mechanisms and clinical correlates. Nat Rev Immunol. (2007) 7:379-90. doi: 10.1038/nri2075

79. Dong Y, Speer CP. Late-onset neonatal sepsis: recent developments. Arch Dis Child Fetal Neonatal Ed. (2015) 100:F257-63. doi: 10.1136/archdischild-2014-306213

80. Lisse IM, Aaby P, Whittle H, Jensen H, Engelmann M, Christensen LB. T-lymphocyte subsets in West African children: impact of age, sex, and season. J Pediatr. (1997) 130:77-85. doi: 10.1016/S0022-3476(97) 70313-5

81. Wood NS, Costeloe K, Gibson AT, Hennessy EM, Marlow N, Wilkinson AR. The EPICure study: associations and entecedents of neurological and developmental disability at the 30 months of age following extremely preterm birth. Arch Dis Child Fetal Neonatal Ed. (2005) 90:F134-40. doi: 10.1136/adc.2004.052407

82. Lauterbach MD, Raz S, Sander CJ. Neonatal hypoxic risk in preterm birth infants: the influence of sex and severity of respiratory distress on cognitive recovery. Neuropsychology. (2001) 15:411-20. doi: 10.1037/0894-4105.15.3.411

83. Skiöld B, Alexandrou G, Padilla N, Blennow M, Vollmer B, Ådén $\mathrm{U}$. Sex differences in outcome and associations with neonatal brain morphology in extremely preterm children. J Pediatr. (2014) 164:1012-8. doi: 10.1016/j.jpeds.2013.12.051

Conflict of Interest: The authors declare that the research was conducted in the absence of any commercial or financial relationships that could be construed as a potential conflict of interest.

Copyright (c) 2021 Bak, Cilieborg, Nguyen, Bering, Thymann and Sangild. This is an open-access article distributed under the terms of the Creative Commons Attribution License (CC BY). The use, distribution or reproduction in other forums is permitted, provided the original author(s) and the copyright owner(s) are credited and that the original publication in this journal is cited, in accordance with accepted academic practice. No use, distribution or reproduction is permitted which does not comply with these terms. 